\title{
Nurses Attitude towards Documentation in Specialist Hospital Sokoto
}

\author{
Mardiyya Ahmad Madugu ${ }^{1 *}$, Auwalu Muhammed ${ }^{1}$, Maryam Ahmad Muhammad ${ }^{1}$, Zulkiflu musa \\ Argungu ${ }^{1}$, and Nasiru Bawa Shagari ${ }^{1}$ \\ ${ }^{T}$ Department of Nursing Sciences, College of Health Sciences, Usmanu Danfodiyo University Sokoto, Sokoto, Nigeria
}

\section{*Corresponding Author}

Mardiyya Ahmad Madugu

\section{Article History}

Received: 13.03 .2021

Accepted: 19.04 .2021

Published: 30.04.2021

\begin{abstract}
Documentation is vital for a safe, ethical, and effective nursing care in clinical setting. Nursing practice requires documentation to ensure continuity of care, planning, and accountability, as well as in the promotion and uptake of evidence-based practice. This study was to assess the nurses' attitude towards documenting nursing care and factors affecting documentation. The study may suggest ways of improving attitude of nurses towards nursing documentation. The study used a quantitative, descriptive survey design in which self-administered questionnaires were distributed to a sample of 199 staff nurses. With the aid of SPSS version 20, data were analyzed using a descriptive statistics. Majority of the participants were females $(70.6 \%)$ and most of the respondents' years of experience are within the range of 6-10 years (29.4\%). Findings shows that nurses have good attitudes towards documentation. However, they disagree that the employees are always reluctant to accept changes in the work process. Also most respondents (83.9\%) agreed that lack of time contribute to nurses' attitude towards documentation. Most of the respondents disagreed that Lack of knowledge may not be a factor affecting documentation (86.1\%). Thus, Proper and effective nursing documentation is very important in hospitals and effective ways of improving nurse's attitude towards documentation should be conducted through seminars and workshops.
\end{abstract}

Keywords: Assessment, Nurses, Attitude, Documentation.

\section{INTRODUCTION}

Nursing encompasses autonomous and collaborative care of individual(s) of all ages, families, group and community, sick or well and in all settings. It includes the promotion of heath, prevention of illness, and the care of ill, disabled and dying people [1]. Documentation is any written or electronically generated information about a client that describe client status, or the care or services provided to that client. Information in nursing documentation should include a complete account of the client's needs, including identified issues and concerns, assessment of findings, care outcomes in order to provide quality and continuity nursing care as well as to measure the degree to which goals are achieved. Nursing documentation started long time ago with work of Florence Nightingale who documented diagrammatically causes of mortality during the Crimean War as sicknesses rather than wounds. He added that, this meaningful message persuaded the military authorities, Parliament, and Queen Victoria to carry out hospital reforms, as well as catapulted nursing and hospital management into the realm of science [2]. A study Confirmed that since this humble beginning, nursing documentation has evolved into being and considered as an essential element in achieving holistic nursing care, and has brought with it the obligation to document not only the performed interventions, but also act of omission, decision making processes among others. This implies that, nursing documentation provides an account of the judgment and critical thinking used in the nursing process [3]. Accurate timely documentation reflects care provided meets professional, legislative and agency standards; promotes enhanced nursing care; and facilitates communication between nurses and other healthcare providers [4].

Many studies have examined nurses' attitudes towards computerization. The studies showed how the implementation of an information system in a healthcare organization can be complex since the introduction of a computerized nursing information system (CNIS). Accordingly, the implementation produced negative attitudes among

Copyright (C) 2021 The Author(s): This is an open-access article distributed under the terms of the Creative Commons Attribution 4.0 International License (CC BY-NC 4.0) which permits unrestricted use, distribution, and reproduction in any medium for non-commercial use provided the original author and source are credited. 
nurses [5-7]. Similarly; a study observed the attitude of nurses towards documentation of nursing care has endangered lives of patients/clients at every level of care [8].

There are number of factors affecting attitude of nurses towards nursing documentation. Some of these factors, are lack of time, lack of knowledge on some systemic of documentation, lack of personnel, motivation, invisibility in nursing work [9]. There was an attempt to improve nurses attitude towards documentation, some of measures taking by the hospital were to address issue of time management, employment of adequate personnel to provide monitoring system to aid in nursing documentation. Examples of nursing care, which are often not documented, include the assessment of nutritional status, risks and/or interventions for the health and safety of their patients, and health teaching. Overall, the systematic nursing approach, which is summarized in the nursing process, is not documented in some healthcare environment [10].

It was observed that nurses' attitudes towards computerization could also depend on how nurses consider the nursing process and nursing diagnosis since most of the CNIS uses them both. Study also demonstrated the existence of a strong correlation between positive attitudes towards the nursing process and an overall positive attitude towards the CNIS. Hence, this study was to assess nurses' attitude towards documenting nursing care and factors affecting documentation in the selected health facility [11].

\section{MeTHODS}

\section{Study Design}

The study used a quantitative, descriptive survey design to examine the attitude of nurses towards nursing documentation of nursing care in Specialist Hospital Sokoto, Nigeria.

\section{Population and sampling}

The nurses of Specialist Hospital constituted the population of this study. Based on the records there were 395 nurses in Specialist Hospital Sokoto. Samples of 199 nurses were selected using stratified sampling technique. The nurses were stratified into wards. A proportionate sampling was used to recruit the required number of nurses in each ward.

\section{Instrument for data collection}

We used a self-administered questionnaire to collect the required data from the respondents. The questionnaire contains four sections. The first section of the questionnaire assessed the personal data of the respondents. The second section assessed the attitude of nurses towards nursing documentation. The third section assessed the factors affecting attitude of nurses towards nursing documentation. The forth section deals with ways to improve attitude of nurses towards nursing documentation.

\section{Data Collection}

Permission was sought from the Medical Director Specialist Hospital, Director Nursing Services and Chief Nursing Officers of various wards prior to the data collection. Each participant was informed about the purpose of the study. The selected participants that consented were giving questionnaire to complete. At the end of data collection, the questionnaires were retrieved for data analysis. Data collection took five days to complete. The completed 187 questionnaires were successfully retrieved from the respondents.

\section{Data Analysis}

Data were analyzed using descriptive statistic (frequency, percentage, mean and standard deviation). A four rating scale (strongly agree, agree, strongly disagree and disagree) was used to determine the level of attitude towards nursing documentation. A decision mean of 2.5 and above was considered agree and below 2.5 is regarded disagree. The measuring scale for the attitude is summarized as follows:

$0.1-2.4=$ poor attitude

$2.5-2.9=$ good attitude

$3.0-3.4=$ very good attitude

3.5 And above = excellent attitude

\section{RESULTS}

\section{Demographic characteristics}

One hundred and ninety nine (199) questionnaires were distributed and 187 were completed and returned by the respondents. Results in Table 1 revealed that $70.6 \%$ of the respondents are females, $25.1 \%$ and $18.7 \%$ of them are NOII and SNO respectively, with $29.4 \%$ having 6 to 10years working experience. On marital status, must respondents (63.6\%) were married. 
Table-1: Personal data of respondents $(\mathrm{N}=187)$

\begin{tabular}{|l|l|l|}
\hline Variables & Frequency & Percentage \\
\hline SEX & & \\
\hline Female & 132 & 70.6 \\
\hline Male & 55 & 29.4 \\
\hline RANK & & \\
\hline NOII & 47 & 25.1 \\
\hline NOI & 27 & 14.4 \\
\hline SNO & 35 & 18.7 \\
\hline PNO & 29 & 15.5 \\
\hline ACNO & 26 & 13.9 \\
\hline CNO & 23 & 12.3 \\
\hline YEARS OF EXPERIENCE & & \\
\hline 1-5years & 44 & 23.5 \\
\hline 6-10years & 55 & 29.4 \\
\hline 11-15years & 39 & 20.9 \\
\hline 20-30years & 31 & 16.6 \\
\hline 30-above & 18 & 9.6 \\
\hline MARITAL STATUS & & \\
\hline Married & 119 & 63.6 \\
\hline Single & 23 & 12.3 \\
\hline Divorced & 19 & 10.2 \\
\hline Widow & 26 & 13.9 \\
\hline & & \\
\hline
\end{tabular}

\section{Attitude of nurses towards documentation}

The attitude of nurses towards documentation (in Table-2) shows an aggregate mean of 3.2 on attitude of nurses towards documentation which is above the decision mean of 2.5. Thus, going by the scale of measurement of attitude, the respondents have very good attitude towards documentation.

Table-2: Attitude of nurses towards documentation $(\mathrm{N}=187)$

\begin{tabular}{|l|l|l|}
\hline Variable items & mean & SD \\
\hline $\begin{array}{l}\text { Documentation of nursing activities and interventions is an indispensable component of nurses' } \\
\text { everyday work. }\end{array}$ & 3.4 & 0.8 \\
\hline Documentation keep nurses away from providing direct patient care & 3.2 & 0.9 \\
\hline Documentation of nursing activities ensure the continuity of care. & 3.6 & 0.8 \\
\hline The employees are always reluctant to accept changes in the work process & 2.2 & 0.8 \\
\hline Documentation of nursing diagnosis is an integral part of the nurses' working routine & 3.2 & 0.7 \\
\hline $\begin{array}{l}\text { Improper documentation decreases patient health safety } \\
\text { Aggregate mean }\end{array}$ & 3.4 & 0.5 \\
\hline
\end{tabular}

\section{Factors affecting the attitude of nurses towards nursing documentation}

Result on Table-3 revealed that lack of time and overload of work, lack of man power and lack of proper supervision are among the factors affecting the nurses attitude towards documentation. However lack of knowledge and lack of nursing note understandable to the discipline are not factors because their decision mean is below 2.5.

Table-3: Factors affecting the attitude of nurses towards nursing documentation $(\mathrm{N}=187)$

\begin{tabular}{|l|l|l|}
\hline Variables & mean & SD \\
\hline Lack of time and overload of work & 3.1 & 0.8 \\
\hline Lack of knowledge & 1.9 & 0.7 \\
\hline Lack of man power & 3.0 & 0.8 \\
\hline Lack of proper supervision & 3.1 & 0.7 \\
\hline Lack of nursing note understandable to the discipline & 1.9 & 0.7 \\
Aggregate mean & 2.6 & \\
\hline
\end{tabular}

\section{Ways for improving the attitude of nurses towards documentation}

Result from Table-4. According to the respondents, the following measures may create positive attitude towards documentation: addressing issues of time management, accountability and proper planning of patient care, available format of documentation of nursing care, employing more personal, and proper monitoring system. 
Table-4: Ways for improving the attitude of nurses towards documentation $(\mathrm{N}=187)$

\begin{tabular}{|c|c|c|c|}
\hline & Variable items & mean & SD \\
\hline & Addressing issues of time management, Accountability and proper planning of patient care. & 3.2 & 0.7 \\
\hline & The unit should have its own format of documentation of nursing care & 2.7 & 0.9 \\
\hline & Employ more personal so that the stress will reduce. & 3.3 & 0.7 \\
\hline & Authority should encourage nurses' motivation & 2.9 & 0.9 \\
\hline 20 & $\begin{array}{l}\text { Proper monitoring system of nursing documentation. } \\
\text { Aggregate mean }\end{array}$ & $\begin{array}{l}3.2 \\
3.1\end{array}$ & 0.7 \\
\hline
\end{tabular}

\section{DISCUSSION}

The study assessed the attitude of nurses towards documentation in specialist hospital sokoto.

Findings revealed that the majority of the nurses were females that fall at the rank of NO11, married and have 610 years of experience.

The study findings show that nurses have very good attitudes toward documentation. This is in line with a research conducted In Nigeria on Knowledge and Practice of documentation among Nurses in Ahmadu Bello University Teaching Hospital(ABUTH)) Zaria, Kaduna State [12]. However, finding was contrary to a study who found that staff nurses had negative attitude towards computer based documentation in nursing [11]. The difference with the current findings may be it is because the research setting is not using computer application but a typed printed document.

The study found that; lack of time and overload of work, lack of manpower and lack of proper supervision are factors that affect the attitude of nurses towards documentation. This is in line with a study which shows that most of the respondents admitted that there are barriers to documentation. Majority of the respondents answered that time constraint were the barriers to nursing documentation. Similarly, in Sweden most of the registered nurses reported lack of time, poor knowledge about documentation, lack of proper documentation facilities, and shortage of staff as barriers toward documentation [12].

Regarding the ways of improving the attitudes of nurses toward documentation the research, correspond with a research conducted in Sweden where most of the respondents suggested that proper training about documenting system and employment of more nurses respectively will help solve the issues of barriers to documentation [12].

\section{CONCLUSION}

The present study found that nurses have positive attitude towards documentation. However, nursing documentation in the study context is constrained by lack of time, overload of work, and lack of proper supervision. Employment of more nurses, and monitoring may improve positive attitude towards documentation among nurses.

\section{REFERENCE}

1. World Health Organisation. (2018). Nursing and Medwifery. Retrieved from: www.who.int/topics/nursing/en/

2. Stinnett, S. (1990). Women in statistics: sesquicentennial activities. The American Statistician, 44(2):74-80.

3. Björvell, C. (2013). Nursing documentation in clinical practice: instrument development and evaluation of a comprehensive intervention programme. Unpublished Thesis. ISBN 91-7349-297-3

4. Priest, C., Kooken, W. C., Ealey, K. L., Holmes, S. I., \& Hufeld, P. (2015). Improving baccalaureate nursing students understanding of fundamental legal issues through interdisciplinary collaboration. Journal of Nursing Law, 11(1):35-42.

5. Smith, K., Smith, V., Krugman, M. \& Oman, K. (2015). Evaluating the impact of computerized clinical documentation. Computers Information Nursing Journal, 23(3): 132-8.

6. Lee, T. T., Mills, M. E., Bausell, B., \& Lu, M. H. (2016). Two-stage evaluation of the impact of a nursing information system in Taiwan. International Journal of Medical Informatics, 77(10):698-707.

7. Smith, D., Morris, A., \& Janke, J. (2017). Nursing satisfaction and attitudes with computerized software implementation: a quasi-experimental study. Computers Information Nursing Journal, 29(4):245-250

8. Moody, L. E., Slocumb, E., Berg, B., \& Jackson, D. (2014). Electronic health records documentation in nursing: nurses' perceptions, attitudes, and preference. Computers Information Nursing Journal, 22(6): 337-44.

9. Galani, M. (2015). Factors affecting nursing information system in residual aged care homes. Retrieved from: https://www.researcgate.net/publication/305650408

10. Mary, G. N., Diane, D., Karen, B. D., \& Pammla, P. (2014). Knowledge and attitude pf select Ugandan Nurses towards documentation of patient care in Uganda. African Journal of Nursing and Midwifery, 2(1), pp. 057-065. 
11. Ammenwerth, E., Mansmann, U., Iller, C., \& Eichstädter, R. (2013). Factors affecting and affected byuser acceptance of computer-based nursing documentation: results of a two-year study. Journal of the American Medical Informatics Association, 10(1): 69-84

12. Hussainat, T. B. (2015). Knowledge and Practice of Documentation among Nurses in Ahmadu Bello University Teaching Hospital (Abuth) Zaria, Kaduna State. Journal of Nursing and Health Science, 4(6):1-6.

CITATION: Mardiyya Ahmad Madugu et al (2021). Nurses Attitude towards Documentation in Specialist Hospital Sokoto. South Asian Res J Nurs Health Care, 3(2): 33-37. 